Plant physiology

\section{Ion channels in plant cells}

from E.A.C. MacRobbie

As IN animals, so in plants, the macroscopic electrical behaviour of cell membranes derives from the transient opening and closing of large numbers of ion channels. The technique of patch clamping ${ }^{1}$, which involves the electrical analysis of a very small patch of membrane that contains only a few ion channels and is sealed on to the tip of a glass micropipette, allows the characterization of a range of ion channels that are permeable to specific ions, including those channels that are associated with excitability. This method can provide very detailed information on the kinetics of channel gating (opening and closing), and its sensitivity to chemical agents or to the voltage across the membrane. Two recent papers ${ }^{2,3}$ mark the promising extension of patch clamping from animal systems to plant cells.

Patch clamping circumvents the problems that have combined to bedevil electophysiological measurements in plant cells-the problems of a very tough cell wall, the existence of plasmalemma and tonoplast membranes in series, and the difficulty of gaining access to the cytoplasm. This is particularly a problem in the cells of higher plants where the cytoplasm forms only a very thin layer sandwiched between the plasmalemma and tonoplast with the result that conditions at either membrane are ill-defined and impossible to control. Because of these problems, electrophysiological measurements in cells of higher plants have remained more primitive than those in animal or giant algal cells.

The two papers now published are very different. Moran et al. ${ }^{2}$, using wheat leaf protoplasts, show the technique to be feasible, but throw little light on membrane properties in physiological conditions. They present a rather confusing range of behaviour in different membrane patches and solutions, without making it clear whether the type of behaviour observed is a function of the particular patch or of the bathing solution. Out of 41 successful patches, 23 yielded discrete current fluctuations, representing the opening and closing of individual ion channels grouped into four classes according to their conductance (10-20 pS, 35-40 pS, 70-100 pS, and $160-180 \mathrm{pS})$. None of the bathing solutions used in the illustrated experiments is in the least similar to the normal cytoplasmic (or external) ion composition; rather their choice reflects the importance of sodium channels in many animal cells.

Why do the other 40 per cent of the patches show only smooth currents, with no indication of the opening or closing of individual channels, and with a very high patch conductance? The authors interpret this behaviour, termed "macroscopic", in terms of "hot spots" in the membrane, with hundreds of channels, each of conductance less than $5 \mathrm{pS}$, in the small area of the patch. In the record they show, this behaviour was observed in $25 \mathrm{mM} \mathrm{LaCl}_{3}$, but it is unclear whether this solution is a prerequisite for the behaviour. The frequency of macroscopic behaviour, if not the result of La treatment, is unexpected. If the conductance of the membrane of wheat leaf protoplasts is in the upper range of values measured in other plant cells, then the existence of even one hot spot would account for the whole cell conductance, and the conductance of a cell with hot spots in 40 per cent of its membrane would be 100-1000 fold higher than that so far observed. Thus, the work on wheat leaf protoplasts signals a major technical achievement, but its significance in a physiological context is not established.

In contrast, Schroeder et al. ${ }^{3}$ start with the firm physiological aim of studying single ion channels in stomatal guard cells (of the bean Vicia faba), in which movements of potassium salts are clearly implicated in the turgor changes responsible for opening and closing of the stoma, through which gases are exchanged. The authors identify a specific $\mathrm{K}^{+}$-selective channel, with a conductance of 20-27 pS, when the cell membrane is bathed with $30 \mathrm{mM} \mathrm{K}^{+}$ on its extracellular side and $228 \mathrm{mM} \mathrm{K}^{+}$ on its cytoplasmic side - concentrations which are likely to be reasonably physiological. At a density of one per $15 \mu \mathrm{m}^{2}$, such channels, open for one-third of the time, could produce potassium fluxes of the observed order. Therefore, they are likely to contribute to the potassium movements associated with guard-cell opening and closing. We eagerly await tests of the sensitivity of this channel's gating kinetics to some of the factors affecting stomatal aperture. Meanwhile, the paper of Schroeder et al. is a landmark in the study of stomatal function.

Finally, it is worth considering which of the ion channels that are known to exist in giant algal cell membranes might now be sought in higher plant cell membranes by patch clamping. First, there is evidence for a voltage-sensitive $\mathrm{K}^{+}$-channel in the cells of Chara and Hydrodictyon, which is closed at the very negative membrane potentials generated by the electrogenic proton extrusion pump (the primary system of active ion transport in plant cells) but which opens at low external $\mathrm{Ca}^{2+}$, high external $\mathrm{K}^{+}$, or at potentials more positive than a threshold value ${ }^{4-7}$. Second, there is evidence for an $\mathrm{H}^{+}$-channel in Chara, which is open at high external $p \mathrm{H}$, at membrane potentials close to the proton equilibrium potential ${ }^{8}$; this channel is involved in the generation of external alkalinity in the pattern of alternating acidic and alkaline zones seen in Chara cells taking in bicarbonate ions subsequent to the photosynthetic fixation of $\mathrm{CO}_{2}$. In addition, two different ion channels are implicated in the action potential in Chara cells-a $\mathrm{Cl}=$ channel and a $\mathrm{Ca}^{2+}$-channel, whose openings allow efflux of $\mathrm{Cl}^{-}$and influx of $\mathrm{Ca}^{2+}$ respectively, both contributing to the depolarizing spike but with different gating characteristics ${ }^{9,10}$. The action potential in Mimosa, like that in Chara, involves net loss of $\mathrm{KCl}^{11-13}$, and it may well be that channels very similar to those in Chara are involved in excitable cells of higher plants.

Thus, there are clearly identified problems awaiting study by the patch clamp technique. The new possibilities for the detailed and well-defined study of cells of higher plants and their range of ionrelated processes are very exciting.

1. Neher, E. \& Sakmann, B. Nature 260, 799 (1976).

2. Moran, N., Ehrenstein, G., Iwasa, K., Bare, C. \& Mischke, C. Science 226, 835 (1984).

. Schroeder, J.I., Hedrich, R. \& Fernandez, J.M. Nature 312 361 (1984).

4. Sokolik, A.I. \& Yurin, V.M. Soviet Plant Physiol. 28, 206 (1981).

. Smith, P. T. \& Walker, N.A. J. Membr. Biol. 60, 223 (1981).

Keifer, D.W. \& Lucas, W.J. Plant Physiol. 69, 781 (1982).

Findlay, G.P. \& Coleman, H.A. J. Membr. Biol. 75, 241 (1983).

8. Bisson, M.A. \& Walker, N.A. J. Membr. Biol. 56, 1 (1980) 9. Beilby, M.J. \& Coster, H.G.L. Aust. J. Plant Physiol. 6 , 323 (1979).

10. Lunevsky, V.Z., Zherelova, O.M., Vostrikov, 1.Y. \& Berestovsky, G.N. J. Membr. Biol. 72, 43 (1983).

11. Oda, K. Plant Cell Physiol. 17, 1085 (1976).

2. Toriyama, H. Cytologia 20, 367 (1955).

13. Abe, T. Bot. Mag. (Tokyo) 94, 379 (1981).

E.A.C. MacRobbie is in the Department of Botany, University of Cambridge, Downing Street, Cambridge CB2 $3 E A, U K$.

\section{IMAGE UNAVAILABLE FOR COPYRIGHT REASONS}

A rod photoreceptor from the retina of a tiger salamander with the outer segment, which is only $10 \mu \mathrm{m}$ in diameter, held in a suction pipette. A patch pipette (right) is used to rupture the membrane of the inner segment so that substances such as calcium chelators or cyclic GMP can be introduced into the cell. Results from these and similar experiments (see pages $579-587$ of this issue) provide strong evidence that cyclic GMP is the internal messenger for phototransduction rather than calcium, complementing the report published in Nature three weeks ago (24 January, p. 310), when the topic was also discussed in these columns (p. 264). (Photo courtesy of T. Lamb). 